\title{
The Health Equity Network of the Americas: inclusion, commitment, and action*
}

\author{
Arachu Castro ${ }^{1}$, Rocío Sáenz², Ximena Avellaneda ${ }^{3}$, Carlos Cáceres ${ }^{4}$, Luiz Galvão ${ }^{5}$, Pedro Mas , $^{6}$ \\ Amy E. Ritterbusch, ${ }^{7}$ and Manuel Urbina Fuentes ${ }^{8}$
}

Suggested citation Castro A, Sáenz R, Avellaneda X, Cáceres C, Galvão L, Mas P et al. The Health Equity Network of the Americas: inclusion, commitment, and action. Rev Panam Salud Publica. 2021;45:e79. https://doi.org/10.26633/RPSP.2021.79

ABSTRACT The Health Equity Network of the Americas (HENA) is a multidisciplinary network that promotes knowledge sharing and intersectoral action for equity in health and human rights in the Americas. The objectives of HENA are: 1) to share successful experiences in the development of interventions, considering the social determinants and determination of health, to achieve participatory and community-based health responses; 2) to analyze the health, social, political, environmental and economic impacts of the COVID-19 pandemic; 3) to identify the effects of pandemic care on populations most at risk because of their age and pre-existing health conditions; 4) examine the situation at borders and population movements in the spread of the pandemic and its effects on migrant populations; 5) propose strategies to ensure access to comprehensive care for pregnant women in order to reduce maternal and neonatal suffering, morbidity, and mortality; and 6) analyze violations of human rights and the right to health of historically marginalized populations, including street dwellers and other communities that depend on public spaces and the street for survival. The analytical and intervention models for health equity at HENA are based on various approaches, including social medicine, social epidemiology, medical anthropology, human ecology, and One Health.

Keywords Health equity; One Health; intersectoral collaboration; social determinants of health; Americas.

\section{The Health Equity Network of the Americas}

The Health Equity Network of the Americas (HENA) is a multidisciplinary network whose objective is to promote knowledge sharing and intersectoral action for health equity and human rights in the Americas. Initially, HENA was based at the University of California Los Angeles (1). In 2020, the network moved to the University of Costa Rica where it forges partnerships with other academic and nongovernmental entities, scientific societies, and international organizations.
HENA fosters a multidimensional analysis model-social determination (2); determinants of health $(3,4)$; well-being (5); health in all policies (6); and planetary health (7) - a perspective that considers the imbalanced interaction between humankind and natural systems to promote health, well-being, and equity and to attain the Sustainable Development Goals (SDGs) developed in the 2030 Agenda for Sustainable Development $(8,9)$. To this end, intersectoral and collaborative implementation of public health, education, and social protection policies is indispensable, along with human security and preservation of the planet.

\footnotetext{
* Official English translation from the original Spanish manuscript made by the Pan American Health Organization. In case of discrepancy, the original version shall prevail. Access to original manuscript: https://doi.org/10.26633/ RPSP.2020.130

1 Tulane University School of Public Health and Tropical Medicine, New Orleans, United States of America. $\bowtie$ Arachu Castro, acastro1@tulane.edu

2 School of Public Health, University of Costa Rica, San José, Costa Rica.

Rosario Castellanos Women's Studies Group, Oaxaca, Mexico.
}

\footnotetext{
4 School of Public Health and Administration, Cayetano Heredia Peruvian University, Lima, Peru

5 Oswaldo Cruz Foundation, Rio de Janeiro, Brazil.

6 Pedro Kourí Institute of Tropical Medicine, Havana, Cuba.

7 Luskin School of Public Affairs, University of California Los Angeles, United States of America.

8 National Academy of Medicine, Mexico City, Mexico.
} 
FIGURE 1. Conceptual framework of the impact of the social determinants of health on health equity

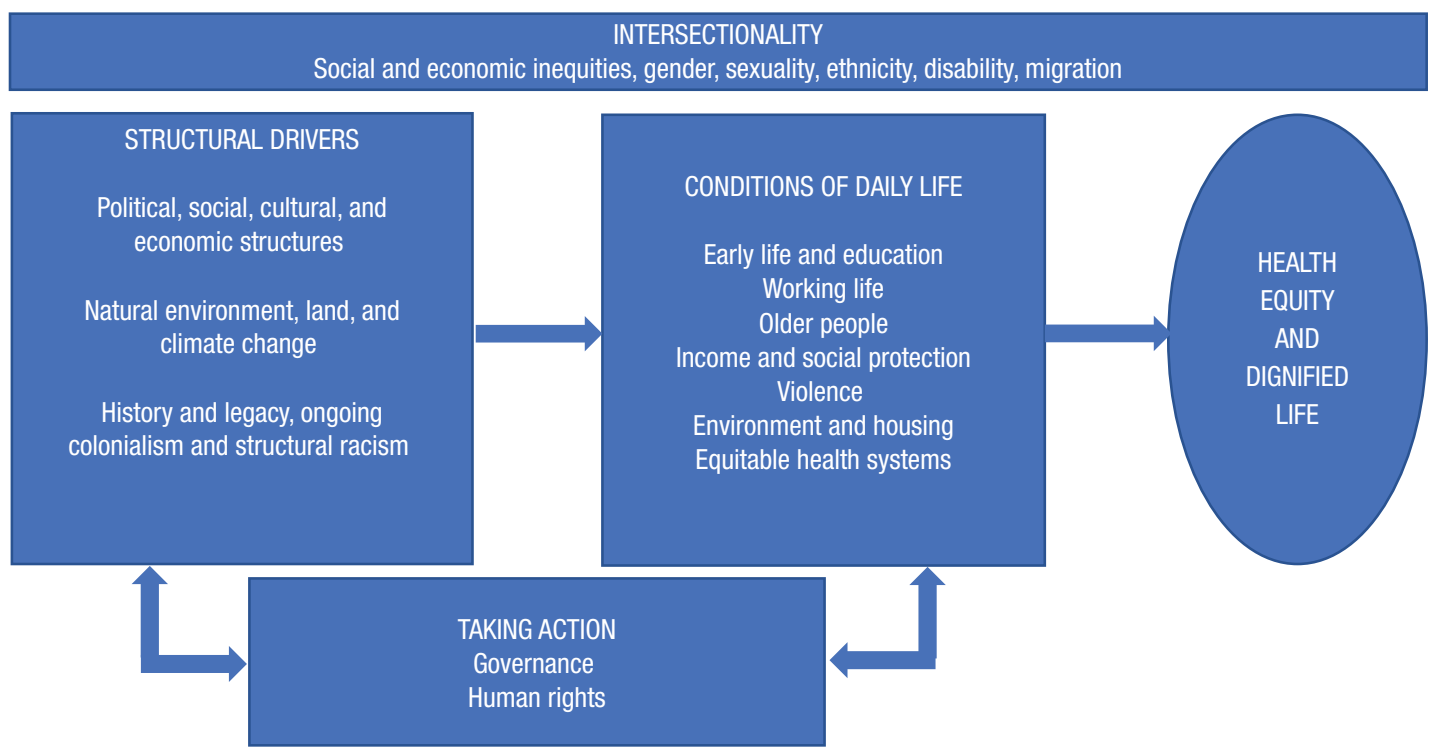

Source: Just Societies: Health Equity and Dignified Lives. PAHO, 2019 (3).

This requires an integrated approach to economic, social, and environmental dimensions, which constitute the social determinants of health (Figure 1).

HENA's theoretical framework includes the concept of health equity whereby all people have the opportunity to reach their maximum potential and, faced with the same need, have equal access to quality health care (10), as well as the concept of health inequity or differences in health that are "systematic, avoidable, and unjust" (11). HENA's analytical and intervention models for health equity incorporate several approaches, such as social medicine, social epidemiology, medical anthropology, human ecology $(12,13)$, and the One Health initiative, which highlights existing synergies by promoting greater cooperation among human, animal, and environmental health (14).

Building equity into national and international public goods in health-such as health systems, public health research institutions, and intangibles such as health promotion and disease prevention, control, and elimination-provides effective means for the pursuit of health equity. All this represents peoples' will and struggles, and in many cases stems from solidarity among people and nations.

\section{HENA's short and medium term objectives}

Share successful intervention experiences, considering social determination and determinants, to achieve engaged community responses for health. In the Americas, health analyses show persistent symptoms of inequity in relation to gender, sexual identity, age, ethnicity, skin color, and socioeconomic status - characteristics that are associated with inequality and social injustice and non-fulfillment of human rights (15-21). Many of the biggest public health problems are concentrated in the poorest and most neglected areas of large cities (22) and in indigenous and Afro-descendant communities (23).

HENA studies health systems with a focus on primary health care (PHC) and community services that provide public health actions, such as in Costa Rica and Cuba (Table 1). Both countries have based their response to the COVID-19 pandemic on PHC, which has been marshaled to continue functioning normally, because contact tracing is done at the community level with active community participation. Both cases show that the most effective pandemic responses come from PHC models embedded in the community and not in hospitals.

In Costa Rica, information on every person, family, and community stored in electronic health records has been used for risk assessment of chronic patients, home delivery of medications, teleconsultation, and electronic monitoring. In addition, a policy was enacted to contact low-risk pregnant women by telephone to confirm that they have received the care they need. If a woman is found to have moderate risk, she should go to a primary health clinic, and if she is at high risk, to a hospital. For COVID-19 care, regional hospitals have been strengthened with personal protective equipment and COVID-19 tests. Everyone who arrives at a hospital has their temperature taken and symptoms assessed; if COVID-19 is suspected, they are directed to an emergency area to separate them from the rest of the people who come in. An area in the National Rehabilitation Center, which has respiratory therapy, was designated for COVID-19 care.

Cuba relies on the strength of its family medicine model and comprehensive PHC services network. From the onset of the pandemic, using a community epidemiological surveillance system, it began case-finding of symptomatic and asymptomatic people, and carried out surveillance of international travelers. This enabled around $50 \%$ of confirmed cases to be found at an asymptomatic stage (24). Contacts of positive cases were advised to remain in quarantine for 14 days at designated hospitals or at home, with restricted movement, monitoring by first-level PHC centers, and PCR testing on the third or fourth day. People with symptoms were referred to hospitals with a higher level of care. At no time did emergency services or intensive care units collapse. Governmental authorities implemented 


\title{
Share successful intervention experiences, considering social determination and determinants, to achieve engaged community responses for health
} Cuba and Costa Rica have been identified as countries in which the public health system is characterized as highly coordinated, based on equitable PHC, with considerable response capacity, and linked to the hospital network $(29,30)$.

\begin{abstract}
Analyze the health, social, political, environmental, and economic impacts of the COVID-19 pandemic
Since the epidemic could continue, reactivate, or give rise to new outbreaks, HENA's efforts are aimed at achieving, at community, national, and regional levels, a deeper understanding with a focus on those who have less access to health and well-being, and on aspects where the lockdown has proven to be unfeasible, unattainable, or clearly harmful to the most vulnerable sectors. The Network tries to identify what changes would have to be introduced-e.g., in food management (31) or in attention to other health problems (32) -in the face of a hypothetical resurgence, to be able to apply measures that do not increase inequity but rather compensate for it and effectively diminish the risk of illness and death. It also seeks to identify civil society responses that have filled gaps or offered important support or constructive criticism of governmental actions not taken.
\end{abstract}

\section{Identify the effects of COVID-19 care on populations at high risk due to age or preexisting conditions}

In Costa Rica, HENA has a strategy to ensure access to medicines for chronic diseases. The Costa Rican Social Security Fund signed a public-private cooperation agreement to use vehicles from rental agencies, the post office, and municipalities with available vehicles, and to provide gasoline and drivers, to distribute medicines to homes and keep people from having to travel. This delivery system includes medicines for chronic diseases, such as antihypertensives, insulin, and antiretrovirals, as well as contraceptives, though it excludes high-risk medicines. The program has been highly rated by the public.

\section{Examine the role of borders and population movements on the spread of the pandemic and their effects on migrant populations}

HENA proposes monitoring the situation in the Amazon region, where difficult and unjust living conditions are inflicted on indigenous nations whose territories have been invaded and whose people are being decimated by diseases such as COVID-19, to which they are particularly vulnerable $(33,34)$.

Propose strategies to ensure access to comprehensive care for pregnant women, in order to reduce maternal and newborn suffering, morbidity, and mortality HENA has identified the Monsignor Sanabria Hospital in Puntarenas (Costa Rica) as a case illustrating a transformation, initiated in 2015, from a biologistic model of care that did not satisfy users toward a woman-centered model of care with a gender perspective and rights approach.

\section{Analyze violations of human rights and the right to health of historically marginalized populations, including street dwellers and other communities that depend on public spaces and the street for survival}

HENA proposes three lines of action for working at street and health-policy levels: 1) Coordinate a regional community board that brings together community voices from different countries in the Americas, including Colombia, Brazil, Argentina, Uruguay, and Mexico, where there are grassroots movements defending the rights of street dwellers, sex workers, and drug users. This board will meet three times a year to coordinate regional actions against state violence and exclusion from the health system that this population experiences. 2) Coordinate a regional system for community reporting negligence in the health system, operating in a live streaming format on HENA's website (with regional community board contact people to speak out about reports). 3) Coordinate a response system that mobilizes public policy and health policy actors to catalyze immediate responses to cases. This system of community reporting and regional network action by HENA is the manifestation of participatory action research that informs our actions.

another group of interventions to accomplish physical distancing by the population in the different stages of the epidemic, focusing more on communities with local outbreaks or a higher number of cases, as well as public information campaigns, all recognized as effective interventions for control of transmission (25).

Other countries of the Region have also implemented successful strategies. In Brazil, for example, the Oswaldo Cruz Foundation (FIOCRUZ) has sponsored projects for the protection of populations most vulnerable to the pandemic (26). This initiative launched a large number of actions that, with modest funding and the commitment of a large number of people and organizations, achieved innovative promotion of health protection, food security, education, social protection, culture, and public health care. FIOCRUZ also develops and produces diagnostic kits and medicines, provides clinical services to people with COVID-19, trains health workers on a large scale, and is moving forward with preparations for development, production, and distribution of a vaccine in Latin America and the Caribbean.

HENA is also urgently seeking and promoting viable medium- and long-term ways to achieve greater equity by identifying agents of transformation that can promote changes through social policies and programs and practices focused on promoting health equity. This sense of urgency has been bolstered by the COVID-19 pandemic, which threatens to reverse achievements toward meeting the 2030 Agenda targets $(27,28)$.
Analyze the health, social, political, environmental, and economic impacts of the COVID-19 pandemic. Due to the COVID-19 crisis, the Americas is facing an unprecedented situation. In almost the entire Region, outpatient services (except for emergencies) were suspended for health problems unrelated to COVID-19 and people were confined to their homes, allowed only brief trips to stock up on food, and required to observe mandatory physical distancing, use of masks, and other measures. Considering the potential negative impact of these restrictions on the national and household economy, some countries offered economic support packages, attempting to prioritize neglected population groups $(27,35,36)$.

In Peru, HENA recognized that the experience with the epidemic and lockdown has differed widely within the country and is always more difficult for people dependent on the informal subsistence economy (e.g., micromarketing, vehicle cleaning/ care, or housecleaning), while the majority of those who have formal employment kept their jobs and income. The most vulnerable frequently lacked bank accounts, delaying transfer of their support subsidies by more than 45 days. They also lacked pensions or 'Compensation for Length of Service' (which functions as unemployment compensation), funds that in both cases were partially released. Consequently, they went hungry, ventured out in search of income to feed their families, and often got infected, some becoming critically ill or dying. Although in their overcrowded homes it was not easy to prevent family members from becoming infected, the media often blamed 
them for their 'irresponsibility' by not 'staying home' $(37,38)$. Very early in the epidemic in Peru, a small group of professionals in public health and the social aspects of health connected on WhatsApp and promptly established contact with the Ministry of Health, organizing weekly virtual meetings to discuss various aspects of the crisis, developing technical briefs for the government, and issuing statements of constructive criticism. Now known as the Citizen Platform for Health Policy-making and Human Rights, it is putting together a long-term vision centered on comprehensive health system reform (39).

In Mexico, HENA collaborates with the Rosario Castellanos Women's Studies Group (GESMujer) in the area of prevention and treatment of violence against women. From the beginning of the isolation period to May 2020, gender-based violence rose $26 \%$ in Oaxaca (40) and the problem has exacerbated the economic situation, since most women have subsistence jobs. On the first day of the quarantine, GESMujer set up a telephone hotline for women, staffed by psychologists and legal advisors, which has handled numerous cases of sexual violence due to the difficulties in seeking medical care given the risk of contagion (40). It has also maintained contact with government agencies that provide other services to victims of violence. Recognizing that the pandemic's effects will have implications for violence and sexual and reproductive health beyond the end of the lockdown, GESMujer will be promoting actions in the areas of prevention, assistance, and monitoring of health and justice services. With regard to prevention and detection of warning signs in cases of violence or sexual and reproductive health, GESMujer will produce audio and video clips with multicultural content, translated into the three major indigenous languages with the collaboration of indigenous leaders trained in the organization. In the area of care, GESMujer will continue to provide psychological and legal counseling, focusing on sexual violence and its consequences. It will also document cases to learn about the care provided in public health and justice services and to make recommendations to government agencies on how to improve their response to women.

Identify the effects of COVID-19 care on populations at high risk due to age or preexisting conditions. In view of the increase in the number of people sick with COVID-19 in the Americas, HENA is involved in activating and strengthening protection, promotion, and prevention systems for the rural and urban population aged $>60$ years (Table 1 ). These are the highest-risk groups when considering hospitalizations and deaths, as their age is related to preexisting chronic diseases $(41,42)$. From a public health perspective, prevention and identification of risk factors are necessary to design strategies for initial and continuing training of health workers and to have appropriate equipment and sufficient supplies in primary care centers (43). It is also necessary to guide and encourage the engagement of community members and the public and private sectors to comprehensively address the health emergency from the perspective of the social determination and determinants of health. Unfortunately, health equity and exclusion are the leading challenges for public health and well-being in this population group. Giving priority to those aged $>60$ years with the participation of PHC health teams is an area of opportunity that should be leveraged during the pandemic, with strategies for prevention, promotion, information, education, and communication of risk factors for comorbidities to prevent infection and reduce demand for treatment services in secondary and tertiary hospitals, which are at greater risk of contamination and transmission of SARS-CoV-2 (44).

Examine the role of borders and population movements in the spread of the pandemic and their effects on migrant populations. There are special situations in border areas where we see both solidarity and human drama as a result of forced migration due to environmental changes and human insecurity. This new threat to indigenous nations, at a time of weakened oversight mechanisms, also threatens the Region's cultural assets. The United Nations has made recommendations and established guidelines to recognize indigenous peoples' representative institutions, authorities, and governments and to include their representatives; provide effective support to indigenous communities to stop the spread of COVID-19; improve the access and management of clean water and sanitation (particularly for indigenous peoples living in remote communities); ensure availability of disaggregated data on indigenous peoples; obtain the freely given, prior, and informed consent of indigenous peoples before initiating any program or activity; establish post-pandemic reconstruction activities and programs that are specifically aimed at indigenous peoples and that support traditional livelihoods; and involve indigenous youth (45).

In Latin America, many factors drive regional migration, and difficult pre- and post-pandemic economic and social conditions make this a growing and unjust challenge. HENA will establish ties to study responses to the pandemic on the borders of the Amazon region (Table 1), in Central America, and between Haiti and the Dominican Republic.

Propose strategies to ensure access to comprehensive care for pregnant women, in order to reduce maternal and newborn suffering, morbidity, and mortality. HENA is conducting research aimed at identifying best practices in the care of pregnant women and challenges to dignified and respectful care; and analyzing the contribution of obstetric violence to inequity in maternal and neonatal health indicators in different population groups in the Americas (Table 1). Verbal abuse, noncompliance with treatment protocols, poor rapport between women and health practitioners, and certain health system conditions and limitations frequently constitute types of obstetric violence (46). This is a critical but neglected issue that requires accurate knowledge of its frequency and impact (47). To ensure optimal health outcomes, the clinical and non-clinical dimensions of obstetric violence must be understood and addressed as drivers of inequity in maternal and neonatal morbidity and mortality, as they can lead to poor or negligent health care delivery $(23,46-48)$. Although maternal death is considered a rare event in epidemiological terms, in the Americas, there are approximately 8500 deaths every year (23 every day), usually as a result of preventable causes (49). These deaths occur disproportionately in indigenous, Afro-descendant, and poor women (21). Learning about successful experiences and their impact on maternal and child health is a great contribution to the development of strategies and programs, both to improve care practices and health-workers' decisions about women's rights and to encourage more women to seek skilled care in childbirth, without fear of violence. 
Analyze violations of human rights and the right to health of historically marginalized populations, including street dwellers and other communities that depend on public spaces and the street for survival. For HENA, it is a priority to elevate the experiences and voices of historically marginalized and socially excluded communities that survive in the midst of extreme poverty, government neglect, and barriers that block access to the right to health at multiple levels (Table 1). The street community includes street dwellers, sex workers, and street vendors who depend on the daily "hustle" to survive. This line of action is informed by the principles and praxis of participatory action research, which we understand as a philosophy of life rather than a research methodology (50). This philosophy recalls the essence of people power and fixes the Network's analytical gaze on the streets, which we understand as a cemetery of extreme poverty, where people die every day from police violence, health system negligence, and stigmatization that criminalizes the bodies of poverty. We want to accentuate the political space of the street as a key sociospatial hub for our participatory action research agenda. Millions of people in the Americas take to the streets, surviving in the exclusion and violence of informal work. During the pandemic, the death of Alejandra "La Monocuco," an Afrodescendant trans woman and sex worker living with HIV in Bogotá, is a tragic example of state violence that happens every day in the Americas (51). Alejandra died 40 minutes after she was abandoned by the ambulance her friends had called in response to a health emergency she was having. Like so many people who survive in the midst of extreme poverty and structural and police violence, Alejandra was one of the millions of people in the Americas who take to the streets to fight for their lives. This historic moment is an opportunity to catalyze institutional changes that will ensure at least a decent life for these communities.

\section{Joining forces}

HENA maintains partnerships with academic and nongovernmental entities, scientific societies, and international organizations, such as the University of Costa Rica; Collaborative Group for Health Equity at Tulane University; Rosario Castellanos Women's Studies Group; Cayetano Heredia Peruvian University; Oswaldo Cruz Foundation; Pedro Kourí Institute of Tropical Medicine, University of California Los Angeles; Investigación en Salud y Demografía (INSAD, Mexico); National Academy of Medicine of Mexico; Pan American Health Organization; Association of Schools and Programs of Public Health; Latin American Alliance for Global Health (ALASAG); University College London's Institute of Health Equity; and the Robert Wood Johnson Foundation, in addition to multilateral agencies.

Networking among HENA's members facilitates socially engaged collaborative research with planned actions for social change aimed at promoting social inclusion, health equity, and human rights in the Americas. The bonds that HENA forms with other institutions make it possible to develop plans for initial and refresher training of human resources for health and to monitor and evaluate interventions aimed at achieving health equity.

Authors' contributions. All the authors conceived the manuscript and contributed to the writing, review, and approval of the final version.

Conflict of interests. None declared.

Funding. None declared.

Disclaimer. Authors hold sole responsibility for the views expressed in the manuscript, which may not necessarily reflect the opinion or policy of the RPSP/PAJPH and/or PAHO.

\section{REFERENCES}

1. Rodriguez MA, Marmot MG, Salgado de Snyder VN, Galvao LAC, Avellaneda X, Saenz M R, et al. The Transformative Potential of Strategic Partnerships to Form a Health Equity Network of the Americas. Ethn Dis. 2019;29(Suppl 1):153-8.

2. Almeida-Filho N. A problemática teórica da determinação social da saude (nota breve sobre desigualdades em saude como objeto de conhecimento). Saude em Debate. 2009;33(83):349-70.

3. Pan American Health Organization. Just Societies: Health Equity and Dignified Lives. Report of the Commission of the Pan American Health Organization on Equity and Health Inequalities in the Americas. Washington, DC: Pan American Health Organization; 2019. Available at: https://iris.paho.org/handle/10665.2/51571.

4. Marmot M. Social determinants of health inequalities. Lancet. 2005;365(9464):1099-104.

5. Plough AL, editor. Advancing Health and Well-Being: Using Evidence and Collaboration to Achieve Health Equity. New York: Oxford University Press; 2018.

6. World Health Organization, Government of South Australia. Adelaide Statement on Health in All Policies. Adelaide: World Health Organization and Government of South Australia; 2010. Available at: https://www.who.int/social_determinants/hiap_statement_ who_sa_final.pdf.

7. Whitmee S, Haines A, Beyrer C, Boltz F, Capon AG, de Souza Dias $\mathrm{BF}$, et al. Safeguarding human health in the Anthropocene epoch: report of The Rockefeller Foundation-Lancet Commission on planetary health. Lancet. 2015;386(10007):1973-2028.
8. United Nations. Resolution A/RES/70/1: Transforming our world: the 2030 Agenda for Sustainable Development. New York: United Nations; 2015. Available at: https://undocs.org/A/RES/70/1.

9. United Nations. 2030 Agenda for Sustainable Development. New York: United Nations; 2015. Available at: https://www.un.org/ sustainabledevelopment/en/.

10. Whitehead $\mathrm{M}$. The concepts and principles of equity and health. Int J Health Serv. 1992;22(3):429-45.

11. Braveman P. Health disparities and health equity: concepts and measurement. Annu Rev Public Health. 2006;27:167-94.

12. Castro A. Health and inequality. In: Callan $\mathrm{H}$, editor. The International Encyclopedia of Anthropology. Hoboken, NJ: Wiley-Blackwell; 2018.

13. Krieger N. A critical research agenda for social justice and public health: an ecosocial proposal. In: B L, editor. Social Injustice and Public Health, 3rd edition. New York: Oxford University Press; 2019.

14. Amuasi JH, Lucas $\mathrm{T}$, Horton R, Winkler AS. Reconnecting for our future: The Lancet One Health Commission. Lancet. 2020;395(10235):1469-71.

15. Dmytraczenko T, Almeida G, editors. Toward Universal Health Coverage and Equity in Latin America and the Caribbean. Evidence from Selected Countries. Washington, DC: The World Bank; 2015.

16. Etienne CF. Equity in health systems. Rev Panam Salud Publ. 2013;33(2):79-80.

17. Cardona D, Acosta LD, Bertone CL. Inequidades en salud entre países de Latinoamérica y el Caribe (2005-2010) [Inequities in health 
among Latin American and Caribbean countries (2005-2010)]. Gaceta sanitaria. 2013;27(4):292-7.

18. de Andrade LO, Pellegrini Filho A, Solar O, Rigoli F, de Salazar LM, Serrate PC, et al. Social determinants of health, universal health coverage, and sustainable development: case studies from Latin American countries. Lancet. 2015;385(9975):1343-51.

19. Cotlear D, Gómez-Dantés O, Knaul F, Atun R, Barreto ICHC, Cetrángolo $\mathrm{O}$, et al. Overcoming social segregation in health care in Latin America. Lancet. 2015;385(9974):1248-59.

20. Barros AJ, Victora CG. Measuring coverage in $\mathrm{MNCH}$ : determining and interpreting inequalities in coverage of maternal, newborn, and child health interventions. Plos Med. 2013;10(5):e1001390.

21. UNICEF and Tulane University. Health Equity Report 2016: analysis of reproductive, maternal, newborn, child and adolescent health inequities in Latin America and the Caribbean to inform policy making; 2016.

22. Diez Roux AV, Slesinski SC, Alazraqui M, Caiaffa WT, Frenz P, Jordan Fuchs R, et al. A Novel International Partnership for Actionable Evidence on Urban Health in Latin America: LAC-Urban Health and SALURBAL. Glob Chall. 2019;3(4):1800013.

23. Castro A, Savage V, Kaufman H. Assessing equitable care for Indigenous and Afrodescendant women in Latin America. Rev Panam Salud Publica. 2015;38(2):96-109.

24. Mas Bermejo P, Vidal Ledo MJ, Baldoquín Rodríguez W, Seuc Jo AH, Guinovart Díaz R, Noriega Bravo V. Lucha anti epidémica en la COVID-19 en Cuba. Organización de la investigación epidemiológica. Información para Directivos de la Salud. 2020;32.

25. Anderson RM, Heesterbeek H, Klinkenberg D, Hollingsworth TD. How will country-based mitigation measures influence the course of the COVID-19 epidemic? Lancet. 2020;395(10228):931-4.

26. Gomez L. Covid-19: Fiocruz lança ações de apoio a populações vulneráveis. Rio de Janeiro: FIOCRUZ; 2020. Available at: https:// portal.fiocruz.br/noticia / covid-19-fiocruz-lanca-acoesde-apoio-populacoes-vulneraveis.

27. Castro A. Challenges posed by the COVID-19 pandemic in the health of women, children, and adolescents in Latin America and the Caribbean. UNDO LAC C19 PDS No. 19. New York: United Nations Development Program; 2020. Available at: https:// www.latinamerica.undp.org/content/rblac/en/home/library/ crisis_prevention_and_recovery/desafios-de-la-pandemia-decovid-19-en-la-salud-de-la-mujer-de-html.

28. Economic Commission for Latin America and the Caribbean. The 2030 Agenda for Sustainable Development in the new global and regional context: scenarios and projections in the current crisis. Santiago: ECLAC; 2020. Available at: https://www.cepal.org/sites/ default/files/publication/files/45338/S2000207_en.pdf.

29. Pan American Health Organization. Healh in the Americas. Washington DC: Pan American Health Organization; 2017. Available at: https://www.paho.org/salud-en-las-americas-2017/?\%20lang=en:

30. Inter-American Development BAnk. El impacto del COVID19 en las economías de la región. La pandemia de COVID-19 en Centroamérica, Haití, México, Panamá y República Dominicana. Washington, DC.: IDB; 2020.

31. FAO, ECLAC. Analysis and responses of Latin America and the Caribbean to the effects of COVID-19 on food systems, No. 2. Santiago: FAO; 2020. Available at: https://www.cepal.org/sites/ default/files/publication/files/45526/ca8872_en.pdf.

32. United Nations. Es vital que la respuesta de los países de América al coronavirus incluya tratar las enfermedades crónicas. UN News, 26 May 2020. Available at: https://news.un.org/es/story/ 2020/05/1474992.

33. Pontes AL, Alarcon DF, Kaingang JD, Santos RV. Vulnerabilidades, impactos e o enfrentamento ao Covid-19 no contexto dos povos indígenas: reflexões para a ação. Rio de Janeiro: FIOCRUZ; 2020. Available at: https:// bit.ly/38FxtZD.

34. Fondo para el Desarrollo de los Pueblos Indígenas de América Latina y El Caribe. Los Pueblos Indígenas ante la pandemia del COVID-19. Primer Informe Regional. La Paz: FILAC; 2020. Available at: https://indigenascovid19.red/archivos/13326.
35. Romo R. Latinoamérica responde al coronavirus: los países que han fallado (y acertado) en su respuesta al covid-19. CNN en Español, 29 May 2020. Available at: https://cnnespanol.cnn.com/2020/05/29/ latinoamerica-responde-al-coronavirus-lospaises-que-hanfallado-y-acertado-en-su-respuesta-al-covid-19/.

36. Economic Commission for Latin America and the Caribbean. Sectors and businesses facing COVID-19: emergency and reactivation. Santiago: ECLAC; 2020. Available at: https://www.cepal.org/ sites/default/files/publication/files/45736/S2000437_en.pdf.

37. Benavente L. Por qué el Perú es el país con más casos por millón de covid-19 en América Latina. RPP Noticias, 18 May 2020. Available at: https:/ /rpp.pe/peru/actualidad/por-que-peru-es-el-pais-con-mascasos-por-millon-de-covid-19-en-america-latina-noticia-1266444.

38. La Torre A, Ghezzi P, Segura A. ¿Qué hacemos cuando el martillo no chanca? La República, 19 April 2020. Available at: https:// larepublica.pe/sociedad/2020/04/19/coronavirus-en-peru-quehacemos-cuando-el-martillo-no-chanca-la-curva-del-covid-19/.

39. Ciriaco M. Una plataforma para defender el derecho a la salud de los peruanos. Salud con Lupa, 9 July 2020. Available at: https:// saludconlupa.com/entrevistas/una-plataforma-para-defenderelderecho-la-salud-de-los-peruanos/.

40. GESMujer. Grupo de estudios sobre la mujer Rosario Castellanos. Available at: https:/ /www.gesmujer.org/web/.2020.

41. Pueyo T. Coronavirus: The Hammer and the Dance: What the Next 18 Months Can Look Like. Medium, 19 March 2020. Available at: https://medium.com/@tomaspueyo/coronavirus-thehammerand-the-dance-be9337092b56.

42. World Health Organization. Joint Mission. Report of the WHOChina Joint Mission on Coronavirus Disease 2019 (COVID19). Geneva: World Health Organization; 2020. Available at: https:// www.who.int/docs/default-source/coronaviruse/who-chinajoint-mission-on-covid-19-final-report.pdf.

43. Ferguson NM, Laydon D, Nedjati-Gilani G, Imai N, Ainslie K Baguelin M, et al. Report 9: Impact of non-pharmaceutical interventions (NPIs) to reduce COVID-19 mortality and healthcare demand. Imperial College London, 16 March 2020. Available at: https://www.imperial.ac.uk/media/imperial-college/medicine/ $\mathrm{sph} /$ ide/gida-fellowships /Imperial-College-COVID19-NPImodelling-16-03-2020.pdf.

44. Ye G, Lin H, Chen S, Wang S, Zeng Z, Wang W, et al. Environmental contamination of SARS-CoV-2 in healthcare premises. J Infect. 2020;81(2):e1-e5.

45. United Nations. The Impact of COVID-19 on Indigenous Peoples. New York: United Nations; 2020. Available at: https:/ / bit.ly/2ZXCbOe.

46. Castro A, Savage V. Obstetric Violence as Reproductive Governance in the Dominican Republic. Med Anthropol. 2019;38(2):123-36.

47. Castro A. Witnessing Obstetric Violence during Fieldwork: Notes from Latin America. Health Hum Rights. 2019;21(1):103-11.

48. Savage V, Castro A. Measuring mistreatment of women during childbirth: a review of terminology and methodological approaches. Reprod Health. 2017;14(1):138.

49. WHO, UNICEF, UNFPA, World Bank, United Nations Population Division. Trends in Maternal Mortality: 2000 to 2017. Geneva: World Health Organization; 2019. Available at: https://www.who.int/ reproductivehealth/publications/maternal-mortality-2000-2017/en/.

50. Fals Borda O, Anisur Rahman M. Action and Knowledge: Breaking the Monopoly with Participatory Action Research. New York: Apex Press; 1991.

51. ¡Queremos la verdad! \#JusticiaParaAlejandra. El Espectador, 6 June 2020. Available at: https://www.elespectador.com/noticias/ nacional/muerte-de-alejandra-monocuco/.

Manuscript received on 18 August 2020. Accepted for publication, after review, on 15 September 2020. 


\section{La Red de las Américas para la Equidad en Salud: inclusión, compromiso y acción}

RESUMEN La Red de las Américas para la Equidad en Salud (RAES) es una red multidisciplinaria que promueve el intercambio de conocimientos y la acción intersectorial para la equidad en salud y los derechos humanos en las Américas. Los objetivos de la RAES consisten en: 1) compartir experiencias exitosas en el desarrollo de intervenciones, considerando la determinación y los determinantes sociales, para lograr respuestas participativas y comunitarias en salud; 2) analizar los impactos sanitarios, sociales, políticos, ambientales y económicos de la pandemia de COVID-19; 3) identificar los efectos de la atención de la pandemia en las poblaciones de mayor riesgo por su edad y las condiciones de salud preexistentes; 4) examinar la situación de las fronteras y de los movimientos de población en la propagación de la pandemia y de sus efectos en las poblaciones migrantes; 5) proponer estrategias para asegurar el acceso a la atención integral de las mujeres gestantes, con el fin de reducir el sufrimiento, la morbilidad y la mortalidad materna y neonatal; y 6) analizar vulneraciones de derechos humanos y del derecho a la salud de poblaciones históricamente marginalizadas, incluyendo habitantes en situación de calle y otras comunidades que dependen de los espacios públicos y de la calle para sobrevivir. Los modelos analíticos y de intervención para la equidad en salud de la RAES se desarrollan desde varios enfoques, como la medicina social, la epidemiologia social, la antropología médica, la ecología humana y el de Una sola salud.

Palabras clave Equidad en salud; salud única; colaboración intersectorial; determinantes sociales de la salud; Américas. 